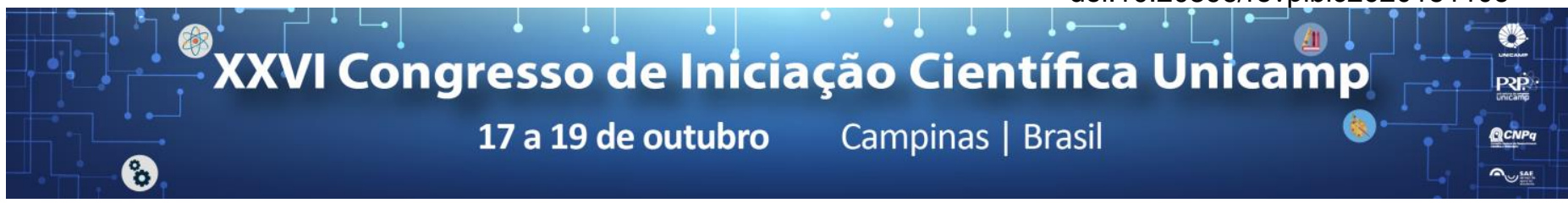

\title{
Análise de Causalidade na Crise Financeira Internacional Sobre os Índices do Mercado de Ações
}

\section{Paloma Menezes Lima*, Rosangela Ballini}

\section{Resumo}

Este trabalho tem como objetivo avaliar a transmissão de choques entre o mercado americano e o mercado de ações de países em desenvolvimento e países desenvolvidos. Para atingir tal objetivo, empregou-se um teste de causalidade na variância, baseado na função de correlação cruzada. Os resultados mostraram quem, em geral, o mercado acionário americano, representado pelo índice S\&P500, desestabiliza os mercados alemão (DAX), chinês (FTSE A50) e japonês (Nikkei 225), aumentando a volatilidade destes mercados durante a crise subprime. No caso do mercado brasileiro (IBOV) apesar de haver uma alta correlação contemporânea entre os índices, os resultados levaram à rejeição da hipótese de que, durante a crise financeira, os movimentos do mercado americano desestabilizaram o mercado de ações brasileiro.

Palavras-chave: crise financeira, modelos de volatilidade, teste de causalidade.

\section{Introdução}

Crise financeira internacional:

- Iniciada em meados de 2007 com a elevação da inadimplência das hipotecas de alto risco (subprime) nos EUA, atingiu as economias ao redor do mundo mediante vários canais de transmissão, envolvendo tanto a esfera comercial quanto a financeira. Impactou de forma heterogênea, conforme a inserção externa de cada uma na economia global.

Objetivo: avaliar a transmissão de choques entre o mercado americano e o mercado de ações de países em desenvolvimento e desenvolvidos, a partir de testes de causalidade na variância.

\section{Resultados e Discussão}

Exercício empírico: estimar a volatilidade dos índices do mercado de ações a partir do modelo de volatilidade condicional univariado GARCH:

- Amplamente adotado na descrição da dinâmica da volatilidade de retornos de séries financeiros

- Maneira eficaz de modelar a incerteza sobre a média de preço dos ativos, isto é, para obtenção da volatilidade dos índices de ações.

Cheung e $\mathrm{Ng}(1996)^{1}$ : propuseram um teste de causalidade na variância dos preços baseado na análise da função de correlação cruzada dos quadrados dos resíduos padronizados das séries dos índices de ações provenientes das variâncias condicionais obtidas pelo modelo GARCH.

Hipótese Nula: não causalidade entre as volatilidades dos indicadores do mercado acionário americano (S\&P500) e demais mercados (IBOV, DAX, FTSE A50 e Nikkei 225).

Hipótese Alternativa: causalidade entre as volatilidades do mercado americano e demais mercados.
- Os resultados indicaram causalidade entre os índices S\&P500 e os índices DAX, FTSE A50 e Nikkei 225.

- Em relação ao IBOV, os resultados apontam para não causalidade, uma vez que não se rejeitou a hipótese de não causalidade entre as volatilidades dos indicadores S\&P500 e IBOV, apesar da alta correlação entre os índices.

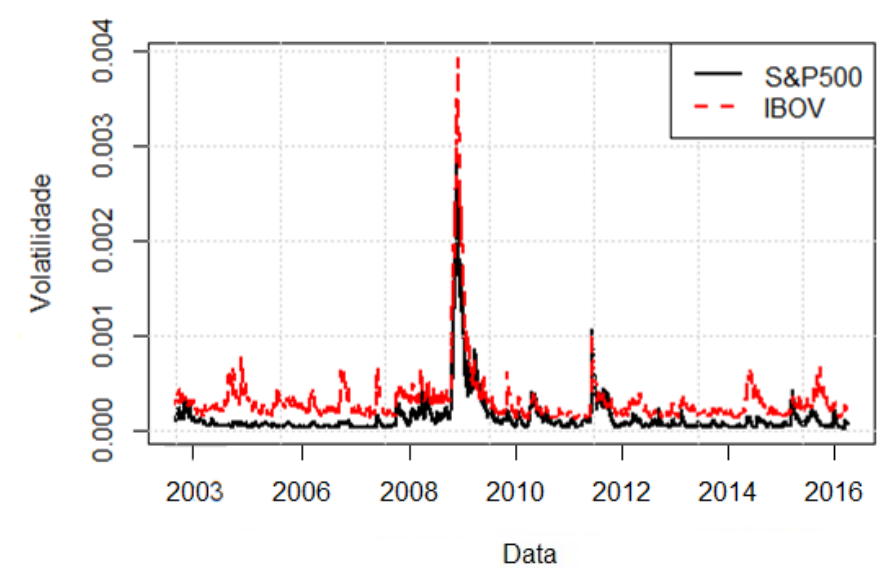

Figura 1. Retornos - S\&P500 e IBOV

\section{Conclusões}

A partir dos resultados obtidos pode-se concluir que há causalidade entre o mercado americano e as volatilidades dos mercados alemão, chinês e japonês. Já em relação ao IBOV, apesar de os resultados não apontarem causalidade entre S\&P500 e IBOV, há uma forte correlação contemporânea entre estes mercados.

\section{Agradecimentos}

Agradeço ao CNPq/PIBIC e pela oportunidade de realizar a presente pesquisa.

${ }^{1}$ Cheung, Y. M. e Ng, L. K.. A causality in variance test and its application to finance market prices. Journal os Econometrics, v. 72, p. 33-48, 1996. 